\title{
Investigating the Role of Psychogenic Shivers in Mental Health
}

\author{
A. Krishnakumar ${ }^{1,2}$, F. Schoeller ${ }^{1,2}$
}

${ }^{1}$ Centre de recherches interdisciplinaires, université Paris Descartes, 75005 Paris, France.

${ }^{2}$ U1001, Institut national de la santé et de la recherche médicale, 75014 Paris, France.

*Corresponding Author: F. Schoeller, Centre de recherches interdisciplinaires, université Paris Descartes, 75005 Paris, France. E-mail: felix.schoeller@gmail.com

\section{Received Date: January 28, 2021; Accepted Date: February 25, 2021; Published Date; March 18, 2021}

Citation: F. Schoeller, Investigating the Role of Psychogenic Shivers in Mental Health. J. Psychology and Mental Health Care. Doi: $10.31579 / 2637-8892 / 070$

Copyright: (C) 2021 F. Schoeller, This is an open-access article distributed under the terms of the Creative Commons Attribution License, which permits unrestricted use, distribution, and reproduction in any medium, provided the original author and source are credited.

\section{Abstract}

The presence of shivering and psychogenic shivering in mental health was measured using a compiled database including the DSM-5 and a large body of existing assessment tools and technology. We found results for chills, tremors, and temperature. None of the other shiver-related terms $(\mathrm{N}=9)$ yielded any results, which suggests that the role of psychogenic shivering in mental health has been largely understudied by physicians and psychiatrists. Based on the results and the data extracted from a complete database of the literature devoted to psychogenic shivers in cognitive neuroscience, we outline the importance of psychogenic shivering in the assessment of mental health in a clinical setting. We discuss how the tools introduced in this article could be developed further to gather new clinical data about both shivers and health.

Keywords : mental health; chills; psychiatry; shivers; psychogenic; chills; database; DSM-5

\section{Introduction}

This article aims to investigate the extent to which psychogenic shivering has been used in psychiatry as either a symptom, a sign, a behavior or a question. The universal, conscious and measurable emotion of psychogenic shivers (shivers of psychological origins rather than thermoregulatory) has attracted significant scientific attention in recent years (figure 1). It is indeed puzzling that a basic survival mechanism such as shivering should be triggered by situations such as music listening (Blood \& Zatorre, 2001), apparently unrelated to its primary vital function (i.e., maintaining the body's temperature stable), while still involving neural correlates such as the amigaloid complex and midbrain dopaminergic neurons (Blood \& Zatorre, 2001). Several theoretical explanation have been proposed (Schoeller et al., 2018). Experimental studies in cognitive neuroscience suggest that the brain reward system

may be involved in psychogenic shivering (Blood \& Zatorre, 2001; Zald \& Pardo, 2002; Salimpoor, 2009; Schoeller, 2016). Current research in engineering and affective computing aims at developing clinical tools using psychogenic shivers (PS) and associated emotions to improve mental health (review in Schoeller et al., in press). Researchers have repeatedly suggested various medical uses for PS stimuli in clinical settings (e.g., Sachs, 2018; Benedek and Kaernbach, 2011, Konečni et al., 2007, Schoeller and Perlovsky, 2016, Sumpf et al., 2015). However, the PS literature contains no direct reference to psychiatry or mental health if one excludes psychogenic fevers (see relevant section) and a few technological devices, which claim to be built for mood disorders (review in Schoeller, in press). To investigate the role of PS in mental health further, we chose to search for direct and indirect references to PS and associated activity and mechanisms (skin activity, thermoregulatory functions, etc.) in mental health questionnaires and assessment tools.

\section{Number of publications $x$ Year}

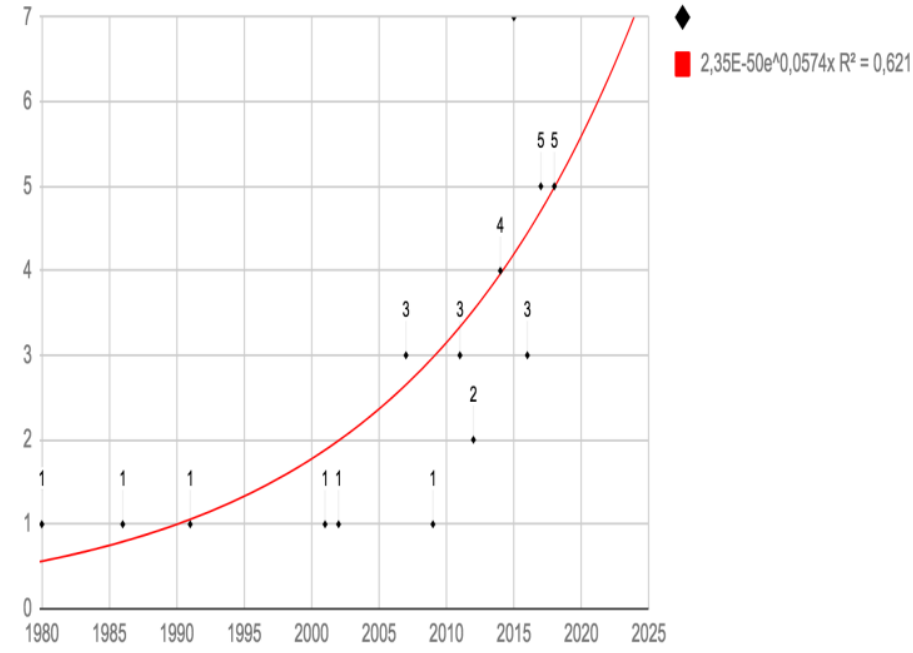

Figure 1 : Number of publications related to psychogenic shivers per year (N total = 38). List of publications accessible at "MindDB.org". 
To explore whether PS has ever been represented as a sign, symptom or in any other category related to disorders, we searched through the DSM5 (A.P.A., 2013), as well as several mental health questionnaires (see full description in the methods section) used in mental health large scale studies.

\section{Methods}

Three major sources were used for this study: the DSM-5 (A.P.A., 2013), a rich set of questionnaires $(\mathrm{N}=94)$ used in two large scale studies aiming to collect clinical data, and a compiled database of all existing literature on PS (see appendix). This represents a total of 3944 questions from 94 questionnaires across 20 domains. These domains are Aggression and Oppositionality, Anxiety, Attention Problems and Hyperactivity, Cognitive and Executive Function, Depression and Mood, Personality Traits, Psychotic and Atypical Behavior, Risk Taking and Impulsive Behavior, Social Interaction, Somatic Complaints, Substance Use and Addictive Behavior, Trauma, Distress Tolerance, Autism Spectrum, General Impairment, Eating Behavior, Sleep, Social functioning, Tics.

\subsection{Sources DSM-5}

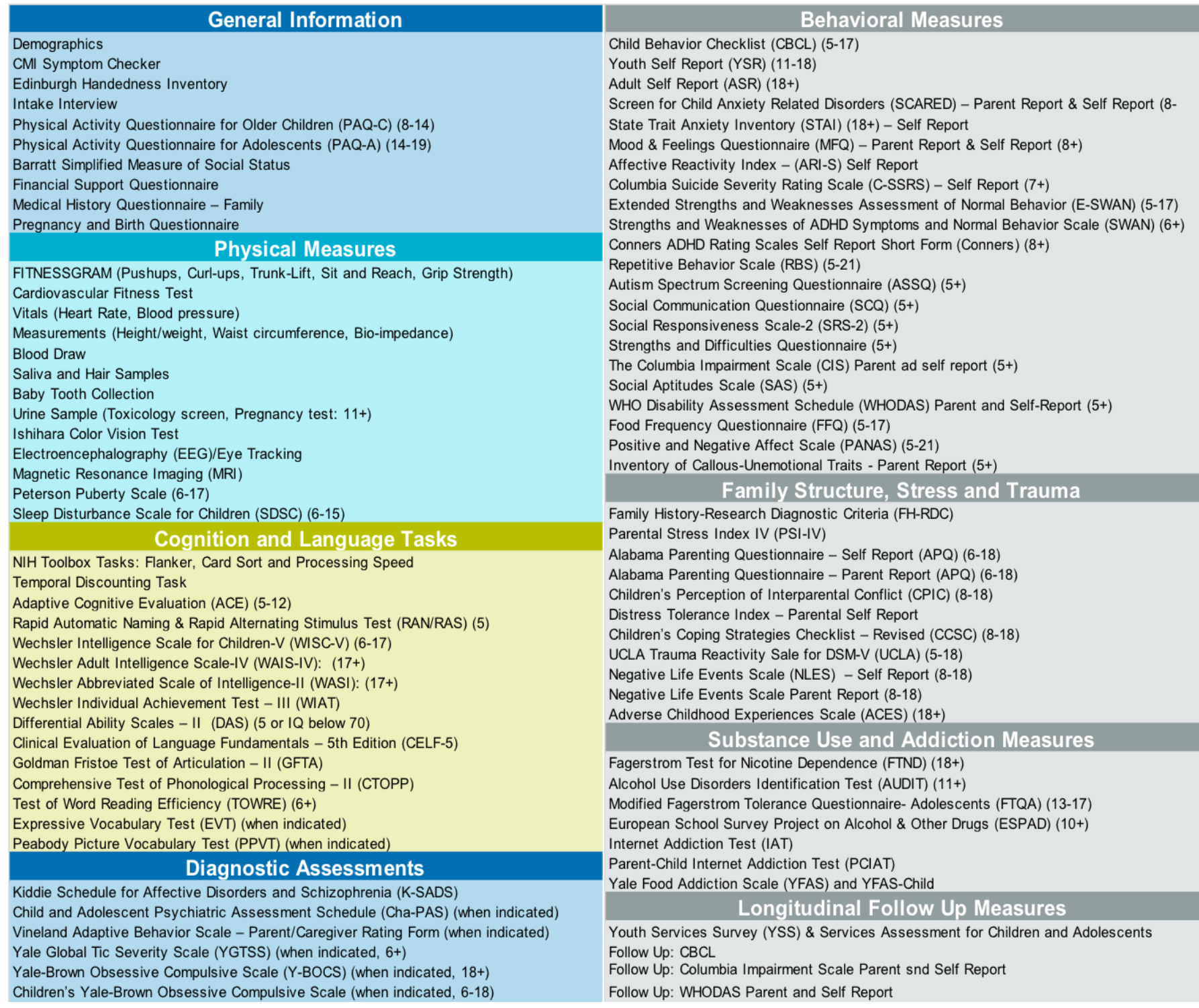

We used two main sources for this study : the DSM-5 and various Mental Health Questionnaires from two large scale studies. The Diagnostic and Statistical Manual of Mental Disorders (A.P.A., 2013) is used by psychiatrists in the diagnosis of mental health disorders in the United States, and elsewhere. It provides a taxonomy for mental health disorders, listing signs and symptoms, diagnostic categories, diagnostic criteria and specifiers, severity, and other information associated with each disorder. The Healthy Brain Network (HBN) and the Nathan Kline Institute Rockland Sample (NKI-RS) are two large scale studies aimed at collecting neuroimaging and clinical data $(\mathrm{N}=10000$ children and adolescents in the case of HBN). The studies release a comprehensive dataset, containing de-identified anonymized data on brain imaging, genetics, psychiatric, behavioral and cognitive information for the scientific community. We selected the list of mental health and behavioural assessments used in the Healthy Brain Network Study and the NKI Rockland Sample Study, as this represents a rich set $(\mathrm{N}=94)$ of commonly used mental health assessments where 35 questionnaires were unique to the HBN, 40 questionnaires were unique to the NKI-RS, and 19 questionnaires that appeared in both.
Child Behavior

Screen for Child Anxiety Related Disorders (SCARED) - Parent Report \& Self Report (8-

State Trait Anxiety Inventory (STAI) $\left(18^{+}\right)$- Self Report

Mood \& Feelings Questionnaire (MFQ) - Parent Report \& Self Report (8+)

Affective Reactivity Index - (ARI-S) Self Report

Conners ADHD Rating Scales Self Report Short Form (Conners) (8+)

Repetitive Behavior Scale (RBS) (5-21)

Food Frequency Questionnaire (FFQ) (5-17)

Positive and Negative Affect Scale (PANAS) (5-21)

Inventory of Callous-Unemotional Traits - Parent Report $(5+)$

Family History-Research Diagnostic Criteria (FH-RDC)

Parental Stress Index IV (PSI-IV)

Alabama Parenting Questionnaire - Self Report (APQ) (6-18)

Distress Tolerance Index - Parental Self Report

Negative Life Events Scale Parent Report (8-18)

Substance Use and Addiction Measures

Fagerstrom Test for Nicotine Dependence (FTND) $(18+)$

(A)

Modified Fagerstrom Tolerance Questionnaire- Adolescents (FTQA) (13-17)

Parent-Child Internet Addiction Test (PCIAT)

Yale Food Addiction Scale (YFAS) and YFAS-Child

Youth Services Survey (YSS) \& Services Assessment for Children and Adolescents

Follow Up: WHODAS Parent and Self Report

Figure 2 : List of assessments used in the HBN study. We excluded assessments that were classified under 'General Information', 'Physical Measures', 'Cognitive tasks', and 'Diagnostic Interviews'. 


\subsection{Lexical analysis}

Based on a lexical analysis of the existing literature (see appendix) and qualitative descriptions from three separate studies (Schoeller \&
Perlovsky, 2016; Schoeller et al., 2018; Schoeller \& Eskinazi, 2018), we queried the sources for psychogenic shivers as well as 12 related terms: chills, tremors, temperature, shivers, goosebumps, piloerection, frisson, feeling of cold, cutis anserina, gooseflesh, horripilation, and thrills.

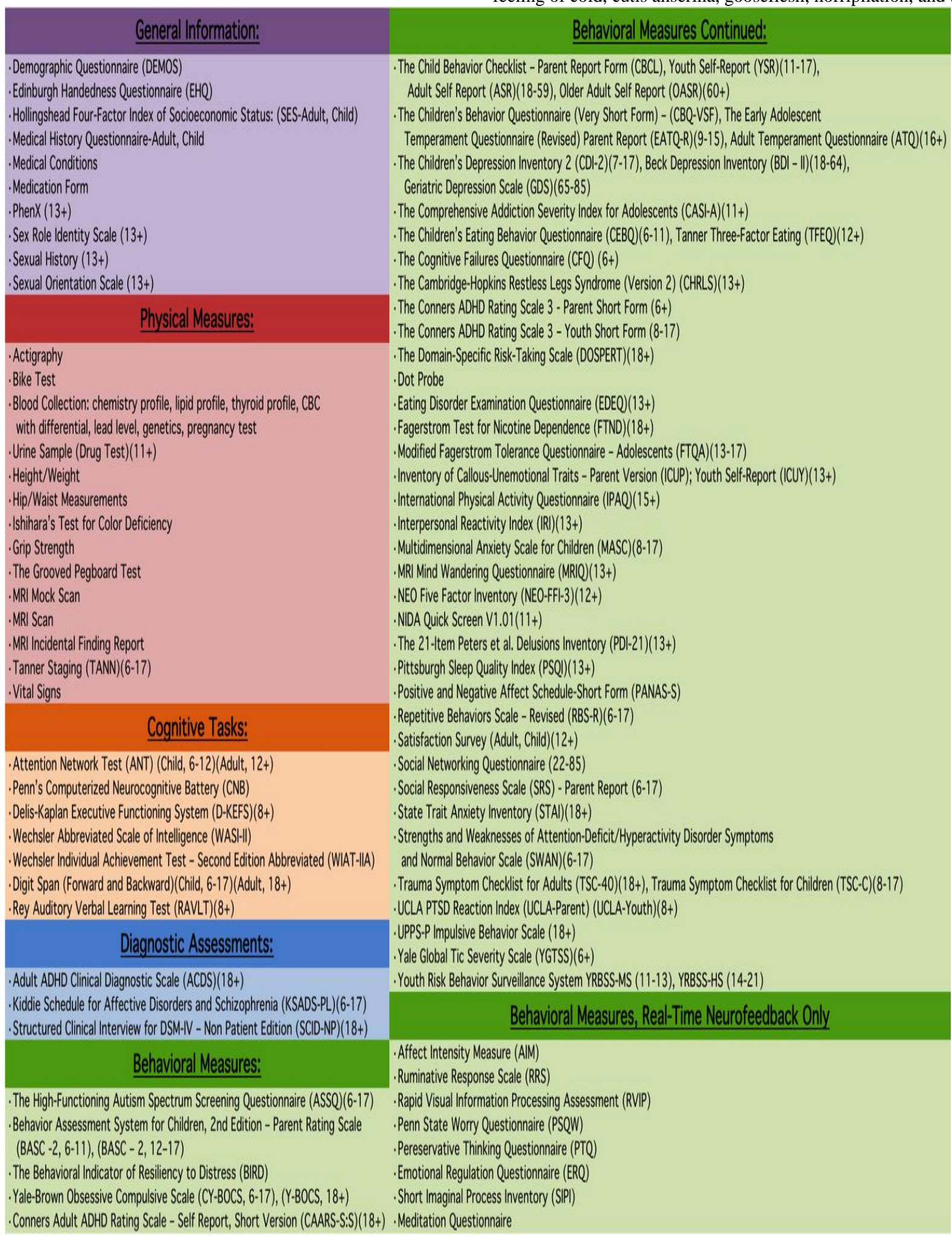

Figure 3: List of assessments used in the NKI study. We excluded assessments that were classified under 'General Information', 'Physical Measures', 'Cognitive tasks', and 'Diagnostic Interviews'. 


\section{Results}

\subsection{Results from DSM-5 analysis}

We first searched for PS-related terms in the DSM-5 (table 1). We found mentions of chills $(\mathrm{N}=3)$, temperature $(\mathrm{N}=4)$, and tremors $(\mathrm{N}=7)$, piloerection $(\mathrm{N}=1)$, and Opioid Disorders $(\mathrm{N}=1)$ as signs for a total of 16 disorders. No results $(\mathrm{N}=0)$ were found for the terms shivers, goosebumps, frisson, feeling of cold, cutis anserina, gooseflesh, horripilation, or thrills.

Chills was found as a for two disorders category: Panic Disorders and Substance Abuse Related Disorders, namely cannabis withdrawal and stimulus intoxication.

Concerning tremors, we found Medication-Induced Postural Tremor, a disorder under the categories "medication induced movement disorders and other adverse effects of medication". Tremors also appeared as an associated feature supporting diagnosis for disorders like childhood fluency disorder (i.e., stuttering) and anxiety disorders. Tremors were also associated with neurological disorders such as conversion disorders, and as a diagnostic marker for substance abuse related disorders, as a sign for withdrawal. Finally, tremors are a sign of neurocognitive disorders like Parkinsons Disease.

Temperature was mentioned under sensory-related responses and activities in autism. The exact symptom is : Hyper- or hypo-reactivity to sensory input or unusual interest in sensory aspects of the environment (e.g., apparent indifference to pain/temperature, adverse response to specific sounds or textures, excessive smelling or touching of objects, visual fascination with lights or movement). Temperature was also mentioned under sensory characteristics of qualities of food, in the context of eating-related disorders. Temperature was mentioned under sleep-wake related disorders as a factor that influences sleep. We omitted the above two search results since it related to the temperature of something external rather than internal.

Temperature was also related with withdrawal symptoms in substance related and addictive disorders, in that temperature regulation was observed for up to 6 months after opioid detoxification. Likewise, withdrawal symptoms were characterized by increases in body temperature along with other signs. Elevations in temperature reflected by breakdown of thermoregulation were associated with the diagnosis of neuroleptic malignant syndrome.

In the DSM-5, piloerection was found under diagnostic criteria of Opioid Withdrawal (292.0; (F11.23)) as one of the sign or symptoms that may be experienced. It was also mentioned that piloerection was more associated with severe forms of withdrawal. Thrill seeking is also mentioned as a consequence of reckless behaviour under post traumatic stress disorders. Thrill seeking is also mentioned as a personality feature associated with diagnostic specifiers of, or co-occuring with conduct disorders.

\begin{tabular}{|c|c|c|}
\hline Terms & Disorder & Symptom/Sign \\
\hline \multirow[t]{3}{*}{ Chills } & Panic disorders & "Chills or heat sensations." \\
\hline & Cannabis withdrawal & $\begin{array}{l}\text { "At least one of the following physical symptoms causing significant } \\
\text { discomfort: abdominal pain, shakiness/tremors, sweating, fever, chills, } \\
\text { or headache." }\end{array}$ \\
\hline & Stimulus intoxication & Perspiration or chills \\
\hline \multirow[t]{4}{*}{ Temperature } & Autism Spectrum Disorders & $\begin{array}{l}\text { "Hyper- or hyporeactivity to sensory input or unusual interest in sensory } \\
\text { aspects of the environment (e.g., apparent indifference to } \\
\text { pain/temperature,...." }\end{array}$ \\
\hline & Opioid use Disorder & $\begin{array}{l}\text { "Subtle changes in cortisol secretion patterns and body temperature } \\
\text { regulation have been observed for up to } 6 \text { months following opioid } \\
\text { detoxification." }\end{array}$ \\
\hline & $\begin{array}{l}\text { Sedative, Hypnotic, or Anxiolytic } \\
\text { Withdrawal }\end{array}$ & $\begin{array}{l}\text { "This withdrawal syndrome is characterized by two or more symptoms } \\
\text { (similar to alcohol withdrawal) that include autonomic hyperactivity } \\
\text { (e.g., increases in heart rate, respiratory rate, blood pressure, or body } \\
\text { temperature," }\end{array}$ \\
\hline & Neurolyptic Malignant Syndrome & $\begin{array}{l}\text { "Extreme elevations in temperature, reflecting a breakdown in central } \\
\text { thermoregulation, are more likely to support the diagnosis of neuroleptic } \\
\text { malignant syndrome." }\end{array}$ \\
\hline \multirow[t]{5}{*}{ Tremors } & \begin{tabular}{|l|} 
Medication-Induced \\
Tremor
\end{tabular} & \\
\hline & \begin{tabular}{|lll}
$\begin{array}{l}\text { Childhood fluency } \\
\text { (stuttering) }\end{array}$ & disorder \\
\end{tabular} & associated feature supporting diagnosis \\
\hline & Anxiety disorders & associated feature supporting diagnosis \\
\hline & Parkinson's disease & symptom/sign \\
\hline & Conversion Disorder & $\begin{array}{l}\text { "With abnormal movement (e.g., tremor, dystonic movement, } \\
\text { myoclonus, gait disorder)" }\end{array}$ \\
\hline
\end{tabular}




\begin{tabular}{|c|c|c|}
\hline & $\begin{array}{l}\text { Alcohol use Disorder and Alcohol } \\
\text { withdrawal }\end{array}$ & $\begin{array}{l}\text { "Other physical signs of heavy drinking and alcohol withdrawal include } \\
\text { tremor," }\end{array}$ \\
\hline & $\begin{array}{l}\text { Substance abuse disorders related } \\
\text { (eg., Sedative, Hypnotic, or } \\
\text { Anxiolytic Withdrawal, inhalant } \\
\text { intoxication) }\end{array}$ & \\
\hline Piloerection & $\begin{array}{l}\text { Opioid Withdrawal (292.0; } \\
(\mathrm{F} 11.23)) \text { as one of the sign or }\end{array}$ & $\begin{array}{l}\text { Piloerection is seen under diagnostic criteria of Opioid Withdrawal } \\
(292.0 ;(\mathrm{F} 11.23)) \text { as one of the sign or symptoms that may be } \\
\text { experienced. } \\
\text { It was also mentioned that piloerection was more associated with } \\
\text { severe forms of withdrawal }\end{array}$ \\
\hline Thrill seeking & $\begin{array}{l}\text { Post Traumatic Stress Disorders. } \\
\text { Conduct Disorders }\end{array}$ & $\begin{array}{l}\text { Thrill seeking is mentioned as a consequence of reckless behaviour } \\
\text { under post traumatic stress disorders. Thrill seeking is also mentioned } \\
\text { as a personality feature associated with diagnostic specifiers of, or co- } \\
\text { occuring with conduct disorders }\end{array}$ \\
\hline
\end{tabular}

Table 1 : Disorders and signs mentioning PS-related terms in the DSM-5.

\subsection{Results from $M H$ questionnaires analysis}

We search for PS-related queries in MH questionnaires (results in table 2). Out of 100 mental health questionnaires taken from the list of assessments in the Healthy Brain Network Study and the NKI Rockland Sample Study. We found results for the terms "chills" $(\mathrm{N}=2)$ and "tremors" $(\mathrm{N}=4)$. These were all the mentions of PS-related terms in the 100 questionnaires examined. Likewise, we found no results for the terms shivers, goosebumps, frisson, feeling of cold, cutis anserina, gooseflesh, horripilation, or thrills.

Two questions directly related to chills were found. One question in the NEO Five Factor Inventory - 3 and one from the E-SWAN study. The question from the NEO relates to aesthetics and poetry whereas the E-
SWAN study maps directly to the symptom "chills and heat sensations" from panic disorders.

We then searched for tremors. "Intensity of Tremors" was a question in the SNAP-4 Rating Scale With Side Effects - Parent questionnaire. Intensity of "Hands trembling" and "Shaky / unsteady" were questions in the Beck Anxiety Inventory. "My hands shake" was a question in the Multidimensional Anxiety Scale for Children 2nd Edition (MASC 2)-Self Report and the corresponding question ("My child gets shaky or jittery") in the parent report. "He/she child gets shaky" and "I get shaky" were questions found in the Screen for Anxiety Related Disorders Parent and Self Reports respectively.

\begin{tabular}{|l|l|l|}
\hline Terms & Questionnaire & Query \\
\hline \multirow{3}{*}{ Chills } & NEO Five Factor Inventory - & $\begin{array}{l}\text { "Sometimes when I am reading poetry or looking at a work or } \\
\text { art, I feel a chill or wave of excitement." }\end{array}$ \\
\cline { 2 - 3 } & E-SWAN & Maintain feelings of a comfortable body temperature" \\
\hline \multirow{3}{*}{ Tremors } & $\begin{array}{l}\text { SNAP-4 Rating Scale With Side Effects - Parent } \\
\text { questionnaire }\end{array}$ & "Intensity of Tremors" \\
\cline { 2 - 3 } & Beck Anxiety Inventory & Hands trembling" and "Shaky / unsteady" \\
\cline { 2 - 3 } & $\begin{array}{l}\text { Multidimensional Anxiety Scale for Children 2nd } \\
\text { Edition (MASC 2)-Self Report }\end{array}$ & "My hands shake" \\
\cline { 2 - 3 } & "He/she child gets shaky" and "I get shaky" & $\begin{array}{l}\text { Screen for Anxiety Related Disorders Parent and Self Reports } \\
\text { respectively. }\end{array}$ \\
\hline
\end{tabular}

Table 2 : Questionnaires and queries involving PS-related questions in the questionnaires.

\subsection{Signs indirectly related to shivers associated to mental disorders}

While conducting the search, we identified several signs related to shivers, which are associated to mental disorders. For example, cutaneous reactions such as skin picking, hallucinations, ants crawling under skin (formication), are found in Depressive Disorder; skin picking is associated with Obsessive Compulsive Disorder, and skin sensations are absent in Conversion Disorder. Among the low-risk phenotypes are the acute alcohol-related skin flush (seen most prominently in Asians) This sign is found under Alcohol Use Disorder.
Dyskinesia Distortion of voluntary movements involves involuntary muscle activity in a similar fashion to the activity of skeletal muscles during psychogenic shivers.

There was an association between hallucination and psychogenic shivers, such as Tactile A Hallucination involving the perception of being touched or of something being under one's skin. The most common tactile hallucinations are the sensation of electric shocks and formication (the sensation of something creeping or crawling on pr under the skin).

A number of neurobiological markers related to psychogenic shivers (e.g., lower heart rate and skin conductance reactivity; reduced basal cortisol 
reactivity; abnormalities in the pre-frontal cortex and amygdala) have been associated with oppositional defiant disorder.

\subsection{Searching for psychiatry terms in chills papers}

We searched for the terms "mental health", "disorder" and "psychiatry" in all the articles related to psychogenic shivers $(\mathrm{N}=39)$ and found no mention of these terms in the majority of them $(\mathrm{N}=30)$. We excluded results where there was a mention of PS terms in the citations, or author information. Several researchers belonging to departments of psychiatry or mental health authored papers on psychogenic fevers, but did not address psychiatry or mental heath in their articles specifically. We also note that in some articles $(\mathrm{N}=4)$, recruited participants were either excluded for, or did not have a mental health disorder.

Direct and relevant results were found in 3 articles. In (Sumpf et al., 2015), under the future perspectives section, it was suggested that the findings could help biofeedback therapies used to treat depression or schizoid personality disorder. In (Oka, 2015), psychogenic fevers were claimed to be observed in anxiety, mood ad borderline personality disorders. The third article (Neidlinger et al., 2017) involved a wearable that was developed for mood and affective disorders.

Indirect references (mentions of the search terms that are not in the context of, or do not relate directly to psychogenic shivers) were found in 3 articles. For example, music was mentioned to benefit mental wellbeing.

\section{Discussion}

We searched for PS-related terms in mental health assessment tools to identify whether this emotion has ever been used in psychiatry as a diagnosis. We found chills, tremors and temperature, piloerection and thrill seeking used in the DSM-5 as a sign for a total of 14 disorders. These were represented over many psychiatric disorders, including PTSD, Panic Disorders, Autism Spectrum Disorder, and Substance Use Disorders. Chills and tremors were also found present in questions of 6 questionnaires commonly used in mental health and in two existing database collected as part of large scale studies on brain imaging, genetics, psychiatric, behavioral and cognitive information. In this section, we first discuss these results and their utility in? psychiatry and behavioral science generally. We then discuss how the existing database can be improved to allow participation from physicians, researchers, patients and the scientific community at large.

We found chills to be related to panic disorders. This is intriguing and should be examined further in relation to negative PS (Halpern et al., 1986 ; Zald \& Pardo, 2002). It is known generally that the relation between temperature and stress is quite old and present even in reptiles (Oka, 2015), a phenomenon described as stress-induced hyperthermia or emotional fever. One plausible explanation for this phenomenon and which should be examined further through physiological studies is the role of the immune system as a general response for stressful situations. Panic disorder chills and negative psychogenic shivers would be instances of emotional fever (Briese, 1991).

Shivering is a muscle tremor, we therefore searched for questions related to tremors in mental health to identify plausible match. We found tremors to be used both as a sign and a symptom. The relation between muscle tremors, anxiety and stress remain to be elucidated. One interesting line of study concerns shivering related to epilepsy, which is a comorbidity for some mental health disorders.

DSM-5 queries related thermal irregularity to opioid detoxification. The anti-opioid Naloxone was found to inhibit positive PS (Goldstein, 1980). Although that latter study's sample size is limited and this study has never been replicated, this is of interest when considering the fact that opioid antagonist such as naloxone often play a role in the formation of new memories and learning (Schoeller, 2015). In general, this demands that the relation between opioid agonists and antagonists, thermal irregularity, stress and learning be clarified.

\section{Conclusion}

As expected, shivering, chills and other thermoregulatory functions sometimes appear in mental health questionnaires. This is true in particular for the NEO Five Factor Inventory. In fact, PS was suggested by the creator of this inventory (McCrae, 2007) to be a universal marker for one of the five personality traits (i.e., Openness to Experience). Given the current interest in the possible role of music for the cognitive system (Matasaka \& Perlovsky, 2013 ; Zatorre, 2003), it is regretting that music is not included in this specific question and we strongly suggest improving this questionnaire to include broader forms of cultural artifacts.

At a broader level, the present study suggests a possibility to centralize all existing data in psychiatry using the questionnaires identified and involving the PS-related query, to perform a meta analysis on a very large amount of data to identify patterns of behavior related to PS (i.e., clinical populations who experience PS at a very high rate or conversely). Given the benefits of PS in neurotypical populations and their relevance for scientific research, this promising discovery holds great promises for the future development of psychiatry.

\section{Acknowledgement}

The authors thank Kishore Sivakumar for his help in building the database.

\section{Contributions}

AK created and queried the mental health database. FS and AK created and queried the PS database. AK wrote the results section. AK and FS wrote the rest of the manuscript.

\section{Conflict of interest}

The authors declare no conflict of interest.

\section{References}

1. American Psychiatric Association. (2013). Diagnostic and statistical manual of mental disorders (5th ed.). Washington, DC.

2. Blood, A. J., and Zatorre, R. J. (2001). Intensely pleasurable responses to music correlate with activity in brain regions implicated in reward and emotion. Proceedings of the National Academy of Sciences of the United States of America, 98(20), 11818-11823. DOI : 10.1073/pnas.191355898

3. Briese, Cabanac, (1991). Stress hyperthermia: physiological arguments that it is a fever. Physiol Behav. 1991 Jun;49(6):11537.

4. Zald, D. H., \& Pardo, J. V. (2002). The neural correlates of aversive auditory stimulation. NeuroImage, 16(3 I), 746-753. DOI: 10.1006/nimg.2002.1115

5. Salimpoor, V. N., Benovoy, M., Larcher, K., Dagher, A., and Zatorre, R. J. (2011). Anatomically distinct dopamine release during anticipation and experience of peak emotion to music. Nature Neuroscience, 14(2), 257-262. DOI : 10.1038/nn.2726

6. Maruskin, L. A., Thrash, T. M., and Elliot, A. J. (2012). The chills as a psychological construct: Content universe, factor structure, affective composition, elicitors, trait antecedents, and consequences. Journal of Personality and Social Psychology, 103(1), 135-157. DOI :10.1037/a0028117

7. Schoeller F, Bertrand P, Gerry LJ, Jain A, Horowitz AH, Zenasni F (2018). Combining virtual reality and biofeedback to foster empathic abilities in humans, Frontiers in Psychology. 
8. Sachs et al., (2016). Brain connectivity reflects human aesthetic responses to music. Social Cognitive and Affective Neuroscience, Volume 11, Issue 6,, Pages 884-891, DOI : 10.1093/scan/nsw009

9. Benedek M, Kaernbach (2011). Biol Psychol. 2011 Mar; 86(3): 320-329. doi: 10.1016/j.biopsycho.2010.12.012

10. Konečni V.J., Wanik R.A., Brown A. (2007). Emotional and aesthetic antecedents and consequences of music-induced thrills. American Journal of Psychology. 120(4):619-643.

11. Sumpf M, Jentschke S, Koelsch S (2015). Effects of Aesthetic Chills on a Cardiac Signature of Emotionality. PLoS ONE 10(6): e0130117. DOI : 10.1371/journal.pone.0130117

12. Fukui and Toyoshima, (2016). Music facilitate the neurogenesis, regeneration and repair of neurons Med Hypotheses. 2008 Nov;71(5):765-9. doi: 10.1016/j.mehy.2008.06.019. Epub 2008.

13. Schoeller, F., Zenasni, F., Bertrand, P., Gerry, L., Jain, A., Horowitz, A., (2019). Combining virtual reality and biofeedback to foster empathic abilities in humans, Frontiers in Psychology, Special issue on positive technology, section Clinical Psychology.

14. Schoeller, F., Perlovsky, L., and Arseniev, D. (2018). Physics of mind: Experimental confirmations of theoretical predictions. Physics of Life Reviews, 25, 45-68. DOI : 10.1016/j.plrev.2017.11.021

15. Schoeller F., Eskinazi, M., Garreau, M., (2018). Dynamics of the knowledge instinct: Effects of incoherence on the cognitive system, Cognitive Systems Research, Volume 47 :85-91; ISSN 1389-0417, DOI : 10.1016/j.cogsys.2017.07.005.

16. Schoeller F., Eskinazi, M., (2018) Psychologie du frisson esthétique. Psychologie Française. DOI: 10.1016/j.psfr.2017.11.003

17. Schoeller, F (2016). The satiation of natural curiosity. International Journal of Signs and Semiotic Systems. 5(2): 2; 200516-032707.

18. Schoeller, F., Perlovsky, L. (2016). Aesthetic chills: Knowledgeacquisition, meaning-making and aesthetic emotions. Front. Psychol. 7:1093. doi:10.3389/fpsyg.2016.01093.

19. Schoeller, F. (2015). The shivers of knowledge. Human and Social Studies, Volume 4, Issue 3, Pages 26-41, DOI: 10.1515/hssr2015-0022.

20. Schoeller, F., Perlovsky, L. (2015). Great Expectations: narratives and the elicitation of aesthetic chills. Psychology, 6, 2098-2102. doi: 10.4236/psych.2015.616205.

21. Schoeller, F. (2015) Knowledge, curiosity, and aesthetic chills. Front. Psychol. 6:1546. doi: 10.3389/fpsyg.2015.01546.

22. Oka et al. (2001). Mechanisms and mediators of psychological stress-induced rise in core temperature. Psychosom Med. 2001 May-Jun;63(3):476-86.

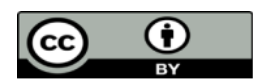

This work is licensed under Creative Commons Attribution 4.0 License

\section{To Submit Your Article Click Here: Submit Manuscript}

DOI: $10.31579 / 2637-8892 / 070$
Ready to submit your research? Choose Auctores and benefit from:

* fast, convenient online submission

* rigorous peer review by experienced research in your field

* rapid publication on acceptance

* authors retain copyrights

* unique DOI for all articles

* immediate, unrestricted online access

At Auctores, research is always in progress.

Learn more www.auctoresonline.org/journals/psychology-and-mentalhealth-care 